\title{
El poder y la comunicación en la sociedad digital
}

Recibido: 25 de octubre de 2010

Aceptado: 27 de mayo de 2011

Publicado: 31 de octubre de 2011
Luis Núñez Ladevéze ladeveze@ceu.es Teresa Torrecillas Lacave teresat@ceu.es (Universidad CEU San Pablo - España)

Resumen: El creciente protagonismo de la información en la sociedad digital reabre el debate sobre las relaciones entre el poder político y la comunicación; recrudeciendo la inquietud sobre las influencias sociales y políticas de los medios y sobre los privilegios de los gobernantes a través de los distintos mecanismos de control de la información. La clave está en distinguir la información de la comunicación para el entretenimiento (propia de las industrias culturales) y recuperar los valores tradicionales sobre los que asentar criterios tanto para delimitar la libertad de expresión propia de la información, como para exigir mínimos de calidad a los contenidos de la comunicación para el entretenimiento.

Palabras clave: Medios de comunicación, información, poder político, libertad de expresión, influencias mediáticas, industrias culturales, comunicación.

Abstract: The growing role of information in the digital society has reopened the debate on the relationship between political power and communication, and intensifies the concern about social and political influences of the media and the privileges of the rulers through various mechanisms to control the information. The key is to distinguish the information from the communications of the entertainment typically of cultural industry and get back on traditional values to establish criteria for both freedom of expression intrinsic to information as to demand the minimum quality of the content of communication to the entertainment.

Key words: Media, Information, Political Power, Freedom of Speech, Media Influences, Cultural Industries, Communication. 


\section{Introducción}

Al considerar las relaciones (no escritas) entre comunicación y poder político, se puede pensar que se trata del aspecto conceptual o de fondo que permite contraponer como algo distinto, por un lado, a la información y difusión de la opinión directamente en la plaza pública, o a través de los medios informativos y la red; y, por otro, al poder político establecido como un sistema de decisiones que vincula a todos los ciudadanos. Pero también se puede pensar que se trata de los aspectos prácticos, de cómo se vive esa relación independientemente de lo que está legalmente establecido y de los problemas concretos que (en cierta fase de la vida democrática) se pueden plantear de modo específico.

El propósito de estas líneas es conseguir relacionar ambas perspectivas (la de los presupuestos discursivos y la de la experiencia profesional) e integrarlas en un enfoque unitario.

\section{Libertad y poder}

Empezando por el aspecto principal, el más inmediato y genérico, cabría preguntarse: ¿hay alguna necesidad de que haya relaciones prescritas entre prensa y poder? Al afrontar ese tema se podrán advertir los aspectos principales de las relaciones presupuestas entre la función de la información en una sociedad (democrática y libre) y el poder político. Una vez estudiado ese aspecto cabrá preguntarse de modo más concreto sobre por qué las relaciones han de ser contrapuestas y sobre el sentido de esa contraposición.

Abordemos la primera cuestión. No es tan obvio que haya necesidad de una relación escrita entre prensa y poder. No está claro, por decirlo de modo concreto, que tenga que haber un reconocimiento expreso del derecho a la libertad de información y de expresión en un texto constitucional ni que sea necesaria una regulación posterior en forma de texto legal. Los del oficio solían decir en España (en los tiempos en que había que convivir con la antigua Ley de Prensa y de Imprenta ${ }^{1}$ ) que la mejor ley de prensa es la no escrita; también se podría añadir ahora que la más contundente formulación del derecho a la libre información es no tener que sancionarlo constitucionalmente. El hecho de que lo haya en algunos sistemas constitucionales, y concretamente en el español, responde, con seguridad, a la peculiaridad del sistema constitucional, al tipo de decisión o de elección realizado para hacer una Constitución de un determinado estilo y concepto.

Esta distinción puede tener o no un valor sistemático. Aquí no afrontaremos esta cuestión. Nos parece que la necesidad de prever un texto legal sobre la libertad de prensa tiene sentido principalmente en aquellas sociedades cuyas tradiciones han sido poco propicias a respetarla, a reconocerla, a fomentarla, como es la española y como lo es, en general, la tradición constitucionalista del Viejo Continente. Pero parece bastante claro que hay una diferencia entre las constituciones continentales europeas y las anglosajonas en este punto concreto. Y la raíz de la diferencia es bastante nítida porque coincide con la distinción entre países en que la libertad política y civil de los ciudadanos surge de una tradición histórica

1.- Ley $14 / 1996$, de 18 de marzo, de prensa e imprenta, que en su primer artículo reconoce el derecho a la libertad de expresión. 
en que germinó naturalmente la democracia, implícita en los hábitos de convivencia y en las costumbres sociales, como ocurre con las democracias anglosajonas, y países que desconfían de su historia precedente que tratan de superar mediante un acto de voluntad constituyente que instaure la democracia como un modo de separarse de un pasado que, con razón suficiente o sin ella, se menosprecia. No es necesario insistir en la obviedad de que este es el caso español, pero creemos que también lo son el francés y el italiano y es posible que el de muchos países iberoamericanos.

Se puede ir más allá de la idea de que la mejor ley de prensa es la no escrita. Más allá fueron Jay, Madison y Hamilton. En uno de los últimos artículos de ese formidable repertorio de textos sobre la naturaleza de la democracia que es El Federalista, dice Publius2: "Afirmo que las declaraciones de derechos, en el sentido y con la amplitud que se pretende, no sólo son innecesarias en la Constitución proyectada, sino que resultarían hasta peligrosas. Contendrían varias excepciones a poderes no concedidos y por ello mismo proporcionarían un pretexto plausible para reclamar más facultades de las que otorgan. ¿Con qué objeto declarar que no se harán cosas que no se está autorizado a efectuar? Por ejemplo: ¿para qué se afirmaría que la libertad de prensa no sufrirá menoscabo, si no se confiere el poder de imponerle restricciones? No es que sostenga que una disposición de esa clase atribuiría facultades de reglamentación; pero es evidente que suministraría a los hombres con tendencias usurpadoras, una excusa atendible para reclamar ese poder [...] y que la disposición que prohíbe limitar la libertad de la prensa autoriza claramente a inferir la intención de dotar al gobierno nacional de la facultad de prescribir normas apropiadas en el caso de dicha libertad [...] A pesar de lo mucho que se ha escrito a propósito de la libertad de prensa: ¿qué significa declarar que la libertad de prensa gozará de una protección inviolable? [...] ¿quién puede dar de ella una definición que no deje un ancho campo a los subterfugios? Afirmo que resulta impracticable y deduzco de esto que la garantía de la referida libertad, a pesar de las elocuentes declaraciones que se inserten en su favor en cualquier Constitución, dependen en absoluto de la opinión pública y del espíritu del pueblo y del gobierno".

Interesa de este párrafo recoger la actitud de inicial confianza en la libertad del ciudadano y contraponerla a la continental europea y, más concretamente, a la española, donde la confianza se desplaza al gobernante cuya función es "proteger" la libertad de los demás y también la propia, por supuesto. Allí se presupone que los ciudadanos conceden el poder a los gobernantes. Aquí, que los gobernantes conceden la libertad a los ciudadanos. Nuestro criterio es que aquella presuposición es válida, pero no esta, porque la libertad es constitutiva de las personas y no puede ser objeto de concesión. Esta contraposición permite, por eso, entender dónde está lo relevante y dónde lo accesorio, si luego hay que avanzar en la discusión. La primera enmienda de la Constitución de los Estados Unidos de América, que fue aprobada por el Congreso durante su primer periodo de sesiones (1791), expresa negativamente un límite a la capacidad de los gobernantes y no una definición protectora de un derecho fundamental de los ciudadanos como hace el artículo veinte de la Constitución española: "El Congreso no hará ley alguna por la que [...] coarte la libertad

2.- "Publius" es el seudónimo con el que se publicaron todos los ensayos de la obra The Federalist Papers en 1787. 
de palabra o de imprenta, o el derecho del pueblo para reunirse pacíficamente". No hay, en la enmienda, derechos fundamentales que definir sino que la inspira la motivación de asegurarse de que el poder de los políticos no se extralimite.

Ese es el problema conceptual latente: el supuesto de que el ciudadano tiende a extralimitarse, mientras que el político tiende a abusar del poder. Si la soberanía procede del pueblo como conjunto de ciudadanos, en principio no es el pueblo el que tiende a abusar de lo que le es propio, sino más bien el recelo ha de enfocarse en sentido contrario.

En la tradición política y la práctica administrativa, esta diferencia de actitud entre unos y otros textos constituyentes se expresa por el sentido que adquieren las palabras "concesión" y "protección". Desde el punto de vista federalista, el pueblo concede atribuciones a los congresistas y al Gobierno, de modo que no es necesario definir derechos porque lo que hay que definir son las atribuciones del gobernante y delimitarlas para asegurarse de que no pueda salirse de ellas. El criterio regulativo de esa "libertad" que se presupone es el de que son las atribuciones de los gobernantes lo que hay que justificar y no los derechos de los ciudadanos lo que hay que delimitar. El gobernante no tiene que proteger derechos que haya concedido porque no es la fuente originaria de esos derechos ni siquiera representante de una voluntad que no es la suya, la voluntad democrática, porque esa voluntad democrática es el resultado de la delegación de las atribuciones que los ciudadanos decidan delegar.

Desde el punto de vista continental, los derechos individuales son reconocidos y delimitados. El gobierno es el depositario de una voluntad democrática que sería irrestricta si no se definieran en la propia Constitución los derechos fundamentales, que se conciben como reserva donde el individuo queda asegurado de la posible parcialidad o extralimitación del poder político. Naturalmente, estamos describiendo una actitud y no estamos muy seguros de cómo se traduce en hábitos concretos, porque para ello habría que hacer algo parecido a un informe sociológico de los comportamientos políticos y ciudadanos en distintas sociedades. No obstante, hay pautas y criterios que permiten dejar bastante bien señalada en qué consiste la diferencia. Y que en ella puede encontrarse alguna explicación de que haya tradiciones, como la española que, aun siendo democráticas, propenden al estatalismo $\mathrm{y}$ al proteccionismo.

El resultado no es sólo que siempre se esté pidiendo algo al Estado o protestando porque el Estado no dé lo que se espera o se cree que debe dar, como si los gobernantes fueran demiurgos o magos que dispusieran de una "varita mágica" para resolver los problemas y atender paternalmente a las necesidades comunes. El resultado es que los gobernantes se atribuyen funciones y competencias que, si se examinan lógicamente, no pueden corresponderles, porque atentan directamente contra cualquier criterio de libertad individual, esté o no definido. De aquí surgen situaciones anómalas y conflictos pragmáticos. Los ejemplos son variados. Pero en el ámbito de la libertad de información (y entendiendo la palabra "prensa" como una sinécdoque por la que nos referimos a los medios de comunicación colectiva, escritos o audiovisuales o por uso de la red) los conflictos han sido patentes. Puede citarse como ejemplo la sentencia del Tribunal Constitucional español del 31 de enero de 1994, según la cual la carencia de regulación legal no puede ser motivo para cerrar emisoras locales, ya que el ejercicio de un derecho fundamental quedaría supeditado a una condición hipotética. 